\title{
OS LUGARES DO CONCEITO DE NAÇÃO NA NARRATIVA DE JOVENS ESTUDANTES DA CIDADE DE PONTA GROSSA: PASSADO, PRESENTE E FUTURO
}

\author{
The Places of the Concept of Nation in the Narrative of Young \\ Students of the City of Ponta Grossa: Past, Present and Future
}

\author{
Giuvane de Souza Klüppel ${ }^{1}$ \\ giuvane_sk@hotmail.com \\ Universidade Estadual de Ponta Grossa. Brasil \\ Data de recepção: 21/02/2019 \\ Data de aceitação: 08/07/2019
}

RESUMO: Parte de um projeto de pesquisa guarda-chuva de âmbito nacional intitulado "o país e o mundo em poucas palavras: narrativas de jovens sobre seus pertencimentos - implicações para o ensino de Ciências Humanas», este texto traz os resultados da análise de 277 respostas de alunos inseridos em quatro etapas de educação formal da cidade de Ponta Grossa, Paraná, Brasil. A consigna «por favor, conte a história do seu país» foi direciona a alunos matriculados em instituições de Ensino Fundamental, Médio, Superior e Pós-Graduação e coletada a partir de questionários de caráter qualitativo. A análise das respostas se deu a partir da disposição dos dados coletados em uma rede semântica de grafos elaborado para visualização em nuvem, possibilitando o exame de evocações e relações estabelecidas entre as palavras-chave dentro do conjunto narrativo. Os sentidos dados ao passado, os agentes da história e o lugar dos próprios narradores foram os elementos enfocados na investigação, que dialoga com os conceitos de consciência histórica (Rüsen, 2007) e narrativa mestra (Carretero; Van Alphen, 2014). Como resultado trazemos um panorama abarcando os elementos que são mobilizados nessa narrativa: suas características gerais, os sentidos dados à história e o lugar em que os alunos colocam a nação no passado (história), no presente (narrativa) e no futuro, a partir de suas expectativas e anseios.

Palavras-chave: narrativa histórica; consciência histórica; narrativa mestra; didática da história; nação.

${ }^{1}$ Graduado em História (UEPG). Mestrando do Programa de Pós-Graduação em Estudos da Linguagem da Universidade Estadual de Ponta Grossa (UEPG). Membro do Grupo de Estudos em Didática da História (GEDHI). 
ABSTRACT: Part of a research project of national scope entitled "o país e o mundo em poucas palavras: narrativas de jovens sobre seus pertencimentos - implicações para o ensino de Ciências Humanas», this paper brings the results of the analysis of 277 answers of students inserted in four stages of formal education of the city of Ponta Grossa, Paraná, Brasil. The issue «please, tell the history of your country" was directed to students enrolled in institutions of Elementary, Middle, Higher and Postgraduate Studies and collected from questionnaires of a qualitative nature. The analysis of the answers occurred from the arrangement of the data collected in a semantic network of graphs elaborated for visualization in cloud, which allows the examination of evocations and relations established between the keywords within the narrative set. The senses given to the past, the agents of history and the place of the narrators themselves were the research-focused elements that dialogue with the concepts of historical consciousness (Rüsen, 2007) and master narrative (Carretero; Van Alphen, 2014). As results, we bring a panorama that encompasses the elements that are mobilized in this narrative, its general characteristics: the senses given to history, and the place where students place the nation in the past (history), present (narrative), and future, from their expectations and longings. nation.

Keywords: historical narrative; historical consciousness; master narrative; history didactic;

SUMARIO: 1. Introdução. 1.1. Quadro teórico. 1.2. Quadro historiográfico. 2. Discussão das Fontes. 2.1. Perfil dos participantes. 2.2. Questões Metodológicas. 2.3. Nação. 3. Considerações Finais. 4. Referências Bibliográficas.

\section{INTRODUÇÃO}

No centro dos estudos contemporâneos em Ensino de História, a expansão dos objetos de pesquisa no sentido de uma descentralização com relação ao exclusivismo de estudos imersos tão somente no espaço escolar, tem se mostrado uma tendência. O que se chama de "Didáctica de la Historia», numa tradução literal para o português, "Didática da História», é um campo de estudos específico, com metodologias, objetos e referenciais teóricos próprios.

Sob os auspícios do campo da Didática da História - e assim também acontece nos estudos recentes de Ensino de História, e Educação - a escola não é mais estudada isoladamente, mas sim a partir da ideia de que seus agentes, por conviverem em diversos espaços, trazem para a escola concepções, ambições e ideais que se formam no universo extraescolar, seja a partir da igreja, da comunidade, das mídias, e em suma de todos os espaços de sociabilidade.

Quando o tema é o estudo de ideias formadas pelos estudantes com relação a determinado assunto - projeto que a presente pesquisa desenvolveu -, essa constante é ainda mais patente, e deve ser constantemente levada em conta, num esforço concreto para se entender como os alunos tem reagido e se apropriado de temas que as instituições de ensino abordam em sua estrutura curricular e na sua prática diária.

Nesse sentido, quando as aulas de história, a partir dos professores e de seus materiais de estudo, dedicam-se a estudar a nação, não é com folhas em branco 
que eles estão se relacionando. De maneira contrária, os alunos já tiveram contato com diferentes noções e projetos de nação que partem de diferentes referenciais, incluso aquelas ideias que derivam dos governos que se encontram no controle do Estado, e dos ideais que fazem parte, originalmente, do Estado moderno, como o próprio nacionalismo e a nacionalidade (Anderson, 1989; Hobsbawn, 1990).

Para o presente estudo, na medida em que se pensa a escola e seus agentes, as aulas de história, seus conceitos, seus temas e sua decodificação, duas atividades são exercitadas. A primeira delas é entender a vida extraescolar em sua totalidade como importante momento de formação histórica informal, seguindo assim a tendência de estudos na Didática da História (Cerri, 2000; Watts, 2000; Lee; Ashby, 2001; Schmidt, 2008; Sant et al. 2015; dentre outros). Outro ponto é justamente refletir sobre as narrativas ufanistas propagadas por intermédio do Estado e em que medida elas passam por processos de apropriação, exclusão e resistência nas narrativas que são elaboradas no interior do espaço escolar - o que materializamos no conceito de master narrative (Carretero; Van Alphen, 2014).

Nesse ínterim, estudar a maneira que os alunos entendem a nação e os elementos que são mobilizados para externar suas concepções, pode ser visto como um primeiro passo no sentido de iniciar a prática de ensinar o passado com uma perspectiva de futuro, conforme sugere o número desta revista. Não apenas porque esta atividade fornece aportes para se repensar o ensino. Mas também porque aquele ufanismo ligado à nação que está tão em voga, chegando a extremos que vêm culminado na ascensão de governos totalitários ao redor do mundo, pode ser entendido e revertido no sentido de se pensar um ensino de História voltado aos direitos humanos e a princípios mais coerentes com as necessidades do planeta.

Mesmo que as instituições de ensino formal não sejam o único espaço de formação histórica, a diversidade que encontramos nesses lugares - expressa na singularidade de cada um de seus agentes: alunos, professores, servidores e comunidade - revela um ótimo espaço para se pensar implicações à disciplina história, e mais ainda ao ensino de história. Essa assertiva toma ainda mais vigor se pensarmos a Didática da História no limiar entre a teoria e ensino da história, no lugar de uma metateoria, que se localiza entre a vida prática e a ciência especializada (Rüsen, 2007 p. 15-16, 35), e seu indiscutível retorno também à disciplina História, fechando assim o curso de uma práxis bem definida.

Dessa maneira, o presente texto traz uma investigação, recorte de meu TrabaIho de Conclusão de Curso apresentado no ano de 2018 na Universidade Estadual de Ponta Grossa (UEPG), sob a orientação do professor dr. Luis Fernando Cerri; e parte de um projeto de pesquisa de âmbito nacional intitulado «o país e o mundo em poucas palavras: narrativas de jovens sobre seus pertencimentos - implicações para o ensino de Ciências Humanas», sob coordenação da professora dr. a Caroline Pacievitch. 
Foram aplicados 277 questionários a alunos matriculados em três instituições de Ensino Fundamental, de Ensino Médio, de Ensino Superior e de Pós-Graduação com sede na cidade de Ponta Grossa, Paraná, Brasil. Os questionários continham, além de algumas informações básicas para reconhecimentos do perfil dos participantes (data de nascimento, sexo, renda familiar, pertencimento étnico-racial e religião), duas perguntas abertas, a serem respondidas pelos jovens da maneira que estes preferissem. A análise que fizemos aqui condiz aos dados coletados referente à seguinte questão "por favor, conte a história do seu país».

Nas próximas linhas o texto se dividirá em quatro partes. Na primeira delas trago algumas reflexões sobre a narrativa, dialogando com os referenciais teóricos que guiaram este trabalho, com ênfase nos conceitos de consciência histórica (Rüsen, 2001), competência narrativa (Rüsen, 2010) e narrativa mestra (Carreteiro; Van Alphen, 2014). Depois, traço o horizonte historiográfico no qual esta pesquisa se localiza e com o qual ela dialoga, mostrando e esclarecendo caminhos que foram escolhidos para realizar o presente trabalho. Em seguida, será feita a análise propriamente dita das fontes, desde o perfil dos agentes participantes até o exame minucioso do material que foi elaborado com os dados coletados. Por fim, reúno algumas considerações finais, traçando perspectivas, possibilidades, e eventuais ressalvas.

\subsection{Quadro teórico}

O narrar não é, nunca, neutro. O indivíduo que se dispõe a se expressar, da forma que for, sobre o tema que for, carrega em suas costas o peso dos ideais, pressupostos e experiências com os quais teve contato durante sua vida, e que interagem constantemente, mediante novas relações, para formar suas convicções. Dessa maneira, uma narrativa elaborada por certo alguém é certamente recheada desse certo alguém na forma de suas ideologias. Em outras palavras, na medida em que a narrativa se relaciona com a vida prática do narrador, a partir dela é possível entender por meio de quem a elaborou, características de sua representação.

Para Jörn Rüsen (2001, p. 149), o ato de narrar é uma prática inerentemente humana. A narrativa, segundo Jerome Bruner (1990, p. 77-80; 1991, p. 4-6), é a estrutura de organização da narração, tanto internamente, no pensamento, quanto externamente, sob a forma de determinada locução, seja oral ou escrita. Dessa maneira, o subterfúgio à estrutura narrativa goza de certa trivialidade já que é cotidianamente o expoente da organização da história produzida e da história pensada, afinal, ela facilita o entendimento da história na medida em que age de maneira a fazer uma espécie de mediação didática, onde determinados elementos são enquadrados em uma estrutura lógica coerente.

Sendo a principal maneira de sistematização da escrita, a narrativa é o local onde podemos encontrar expressa a consciência histórica de maneira organizada 
(Rüsen, 2001, p. 61-67). Por consciência histórica, entendemos, a partir de Rüsen (2001, p. 57), o conjunto de operações, inerentes ao pensamento humano, a partir dos quais os indivíduos atribuem sentido ao presente, através da interpretação do (seu) passado histórico, e que tem como produto a orientação do seu agir no presente visando um determinado futuro.

No centro do processo de constituição da consciência histórica está a «competência narrativa», ou seja, a capacidade atribuída à consciência humana de conferir sentido ao passado a partir da orientação temporal da vida prática por meio da experiência passada (Rüsen, 2010, p. 59). A ação de dar sentido ao passado, porém, passa por uma narração histórica. Uma narração histórica pode ser entendida como uma explicação histórica (Rüsen, 1987, p. 97). Toda explicação, por sua vez, é narrativa. É narrativa em forma, histórica em conteúdo e explicação em função².

Para Rüsen (2010, p. 59-60), a narração histórica é constituída entorno de três outras competências que dizem respeito à forma, ao conteúdo e à função. Elas de certa maneira traduzem o que é e como funciona a consciência histórica. A primeira delas, ligada à forma, é a competência de interpretação que se refere à apreensão do passado pelo passado, em sua dimensão temporal específica, diferenciando-o do presente. A segunda é chamada de competência de experiência, e constitui o entendimento da relação entre as três dimensões temporais a partir do presente, que traduz experiências e traça perspectivas. Por fim, associado à função, a competência de orientação - que se refere à orientação temporal - entendendo-se a mudança de tempo e a localização concreta do sujeito.

A partir das operações da consciência histórica e, tendo em mente que para além de uma interpretação, a narração implica também uma representação - o que podemos definir como uma forma de atribuição de sentido (Silva, 2000, p. 91) -, a dimensão moral da consciência, a atribuição de sentido mesma, divide a consciência histórica em quatro diferentes tipos, que não são estanques, mas que dizem respeito às estruturas de pensamento que os sujeitos elaboram com a finalidade de orientar sua compreensão de temas que carecem de uma investigação histórica interna.

Podemos dizer que existe uma gradação entre esses tipos. Entretanto eles não são alcançados por meio de uma "evolução». O fio que delineia essa gradação, é a criticidade (Rüsen, 2015, 253-257), onde seu grau máximo pode ser entendido como a capacidade de perceber mudanças temporais que acompanham estruturas materiais e imateriais. Os "níveis» apreendem a forma como ocorre a atribuição de sentido dada a determinado assunto. O primeiro desses níveis é chamado, dentro da tipologia de Rüsen (2007, p. 43-63; 2010, p. 61-71), de tradicional. Nele, a

2 Podemos ir além e pensar que toda explicação é histórica ao mesmo tempo que narrativa: histórica na medida em que evoca elementos passados, no momento em que se estrutura a partir de uma lógica temporal e/ou causal; narrativa é a forma linguística de locução. 
constituição narrativa de sentido se organiza de maneira a orientar a vida prática por meio da presença da representação do passado no presente. É a tradição quem guia o sujeito no processo de orientação temporal.

Na medida em que a tradição torna-se insuficiente como meio de orientação no tempo, outros referenciais passam a guiar os sujeitos. O modo de constituição de sentido exemplar se caracteriza pelo resgate e a abstração de modelos presenciados no passado, para o presente. Quando a lógica de modelos é deixada para trás, e a orientação é dada por uma argumentação histórico-crítica baseada, estabelece-se o tipo crítico. 0 modo genético, por fim, é dado quando, acompanhado de argumentação crítica, o tempo, assim como todas as estruturas estabelecidas no tempo, passam a ser visto como mudança. Aqui, a narrativa coloca "o momento de mudança temporal no centro do trabalho de interpretação histórica» (Rüsen, 2007, p. 58).

Essa tipologia serve para definir a relação estabelecida com qualquer assunto que tenha como interlocutor o passado. Serve, de igual maneira, para a ideia de nação, conforme utilizamos nesse trabalho. Como é que a nação é entendida pelos jovens de nossa pesquisa? Quais são os elementos mobilizados pelos mesmos para contar sua história? Essas são duas das perguntas que tentamos responder ao longo desse trabalho. De antemão, porém, Mario Carreteiro e Floor Van Alphen (2014), a partir do conceito de master narrative, vão nos dizer que discursos sobre a história do próprio país carregam fardos que derivam da consolidação dos Estados-nação, desde a construção de uma identidade nacional.

Em menor ou maior grau, e de formas diversas, características da narrativa mestra aparecem na narrativa dos estudantes. É oportuno entender, porém, como elas são consumidas pelos mesmos, com apropriações, exclusões ou resistências a partir de contra narrativas. A master narrative pode ser sintetizada entorno de quatro características, a saber: a organização de narrativas em termo de inclusão e exclusão; o estabelecimento de uma identidade compartilhada e anacrônica entre o narrador e o passado histórico prescrito (a partir da utilização dos pronomes "nós» e «eles», por exemplo); a construção das narrativas entorno de temas que podem assumir caráter teleológico e minimizar ou esconder certos temas e sujeitos; associação de uma visão romântica da concepção da nação e da nacionalidade, entendendo-as como uma essência preexistente ao próprio Estado-nação.

Essas características revelam uma visão anacrônica e tendenciosa que tem como objetivo legitimar a história como objeto para identificação nacional (Carretero, Van Alphen, 2014, p. 293). O contrário disto, ou seja, a formação de contra narrativas, derivam de uma consciência histórica crítica, que, segundo Rüsen (2007, p. 56) «(...) desestrutura narrativas mestras e rompe com os constructos categoriais, destruindo conceitos-chave, categorias e símbolos» (Rüsen, 2007, p. 56). É com o auxílio destes dois referenciais que faremos a análise de nossas fontes, podendo assim situa-los dentro das discussões do campo da Didática da História. 


\subsection{Quadro historiográfico e metodológico}

Existem diversas maneiras já consolidadas na historiografia de se fazer a coleta de narrativas. Através de relatos orais ou por escrito, perguntas, quando submetidas a determinado grupo, são, no geral, ou quantitativas ou qualitativas. A primeira delas, permite respostas objetivas, onde o participante escolhe entre respostas pré-determinadas pelo pesquisador. Elas podem ser escalas de concordância/discordância, relações entre assertivas diversas, ou respostas fechadas simples.

Com relação a este meio de sondagem, podemos citar como exemplo o esforço de dois projetos que envolveram dezenas de instituições e centenas de pesquisadores. O primeiro deles é o Youth and History, uma iniciativa desenvolvida nos anos 1990 pela Associação Europeia de Professores de História (Euroclio) e pelo Comité Europeu da Cultura e da Educação (CULT), que desenvolveu um projeto comparativo reproduzido em 27 países europeus no qual 32 mil estudantes de idade entre 15 anos projetaram seus conhecimentos e suas visões sobre a história (Watts, 2000 p. 179). Já o Jovens e a História no Mercosul, foi um projeto que, em sua aplicação definitiva durante os anos de 2012-13, recolheu cerca de 4 mil questionários de estudantes entre 15 e 16 anos residentes na Argentina, Brasil, Chile, Paraguai e Uruguai, com o objetivo de avaliar aspectos do ensino, da aprendizagem e do pensamento histórico no interior da consciência histórica e da cultura histórica dos jovens de maneira a levantar dados para embasar discussões e deliberações relativas ao ensino de história; informações foram recolhidas em escolas com diferentes perfis (pública de excelência, pública central, pública de periferia, pública rural, privada laica comunitária, privada laica empresarial e privada confessional) a partir de questionários quantitativos compostos de 49 questões que versavam sobre as mais variadas temáticas (Barom, 2016, p. 72-78; Cerri; Amézola, p. 33,38-39, 2007).

Dos trabalhos que lidam com a narrativa na perspectiva da coleta oral, cito a tese do professor Dr. Luis Fernando Cerri defendida em 2000, intitulada «Ensino de história e nação na propaganda do 'milagre econômico'», que, gerando o contato de um grupo de idosos com fontes publicitárias veiculadas por revistas de circulação nacional num recorte entre 1969-73, examinou a recepção e a reelaboração do sentido presente nessas mensagens por parte desses indivíduos que viveram esse período (Cerri, 2000). Podemos citar ainda o trabalho realizado por Kusnick e Cerri (2014), que se propôs a analisar as matrizes conceituais predominantes no pensamento dos estudantes quando dentro do processo de aprendizagem escolar de história. Três tópicos (1. "Quando eu falo 'história' o que vem na cabeça de vocês?»; 2. "Como era a vida há 50 anos?»; 3. "Como vocês pensam que será a vida daqui a 50 anos?») organizaram uma discussão que gerou 271 minutos de conversação ocorridas no interior de 5 grupos dentro dos quais foram distribuídos 39 alunos do ensino médio público regular de idades entre 14 e 19 anos e da Educação de Jovens e Adultos. Outra pesquisa que anda por caminhos semelhantes é 
o estudo realizado por Mario Carretero e Floor Van Alphen com estudantes do 8ㅇ e do 11 으 grau da escola pública Argentina pertencentes à classe média urbana. 0 procedimento foi realizado através de entrevistas individuas onde buscou-se obter narrativas sobre eventos políticos relacionados à construção da identidade nacional (Carretero; Van Alphen, 2014).

O outro meio de investigação empregado é assentado em questionários com perguntas abertas, descritivas, com indagações que permitem livre resposta por parte dos participantes. O que é analisado neste caso são os elementos dispostos no interior das estruturas narrativas produzidas. Os exemplos existentes são, como nos outros casos, bastante vastos. Menciono como ilustração o estudo desenvolvido na Catalunha por Edda Sant, Neus González-Monfort, Antoni Santisteban Fernández, Joan Pagès Blanch e Montserrat Oller Freixa (2015), que teve como foco analisar como estudantes catalães que recém terminaram a educação primária narram a história da Catalunha, comparando as narrativas produzidas por eles com a narrativa oficial catalã. Neste caso, a questão «O que você sabe sobre a história da Catalunha?» foi o alicerce que conduziu a elaboração das narrativas. Dentro dessa estrutura destacamos ainda os trabalhos de James Wertsch (1994), Maria Auxiliadora Schmidt (2008) e Isabel Barca e Schmidt (2013).

A escolha deste último procedimento para nosso estudo deriva do fato de que, de um lado, a pesquisa qualitativa traz possibilidade de análise que podem salientar minúcias que não são obtidas em perguntas objetivas, e de outro, o levantamento oral não se adéqua à metodologia de sistematização e análise das fontes utilizadas por nós, ao mesmo tempo em que não seria exequível nos termos de abrangência propostos. Além disso, é importante destacar que nosso trabalho deriva de um projeto guarda-chuva intitulado «O país e o mundo em poucas palavras: narrativas de jovens sobre seus pertencimentos - implicações para o ensino de Ciências Humanas», sob coordenação geral da professora Dra. Caroline Pacievitch que estabelece bases que visam gerar uniformidade de levantamento e analise nas sondagens que ocorrem simultaneamente em cinco municípios brasileiros, a saber, Aracaju, Goiatuba, Morrinhos, Ponta Grossa e Porto Alegre. De resto, vale mencionar que todos os empreendimentos apontados anteriormente serviram de base para o trabalho desenvolvido aqui.

Dentro dos questionários utilizados por nós haviam duas consignas: «por favor, conte a história de seu país», e; "por favor, escreva o que você sabe sobre o desenvolvimento da democracia em seu país». Para este trabalho, analisaremos as 277 respostas coletadas relativas somente à primeira delas.

O processo de sistematização das informações coletadas fez uso da metodologia desenvolvida por Edson Armando Silva e Joseli Maria Silva (2016), e ainda Edson Armando Silva et al. (2017). A partir dela foram criados grafos de organização em nuvem, onde foi possível visualizar a relação estabelecida entre palavras-chave dentro das narrativas. Esse processo começou com a transcrição das narrativas 
para o processador de texto LibreOffice Writer. Isto feito, foram arrumados erros gramaticais e juntadas as palavras compostas a partir da utilização de "_" no lugar de backspaces entre as mesmas.

O próximo passo foi copiar o texto com as alterações realizadas para uma planilha eletrônica dentro do LibreOffice Calc. Ali, cada frase foi alocada em uma linha no interior de uma tabela. Depois, as informações foram movidas para o programa OpenRefine, com o propósito de promover uma «limpeza» das narrativas. Essa segunda etapa consistiu na retirada de informações que não assumem relevância para a análise em rede e que podiam acabar poluindo os grafos, dificultando sua leitura. Além da retirada de pontuações, foram feitas padronizações de termos e palavras (palavras em diferentes tempos verbais, com radicais diferentes e no singular/ plural ou masculino/feminino, por exemplo, são lidas como elementos diferentes pelo programa, mas muitas vezes guardam um mesmo sentido), e ainda a retirada das stopwords, ou seja, palavras que não apresentavam significado para a pesquisa quando analisadas isoladamente (aqui entram, por exemplo, preposições, artigos, conjunções e advérbios).

Por fim, foram feitos os procedimentos na ferramenta de manipulação de grafos, Gephi. O propósito então foi criar um grafo para análise da relação entre as palavras no interior de nosso conjunto narrativo. Os resultados podem ser verificados nas linhas seguintes.

\section{DISCUSSÃO DAS FONTES}

\subsection{Perfil dos participantes}

Dentre os 277 alunos participantes da pesquisa existe uma preponderância de pessoas do sexo feminino, somando 153 pessoas. Outras 121 são do sexo masculino, enquanto 3 não responderam. Com relação à etnia/raça a maior parte se declara branco, somando 104 respostas, depois pardo, com 64. Nessa fase 83 participantes não responderam a questão sobre seu pertencimento. Outros 26 se identificaram como negro, amarelo, moreno, preto, castanho, caucasiano, entre outras denominações.

Com relação à renda familiar, a maior parte dos respondentes se enquadra com uma renda entre $\mathrm{R} \$ 700,00$ e $\mathrm{R} \$ 3.500,00$, somando 68 pessoas. Outros 41 jovens declararam renda familiar entre $\mathrm{R} \$ 3.501,00$ e $\mathrm{R} \$ 6.999,00$. A maior parte, porém, 151 participantes, não respondeu a essa pergunta. As demais respostas figuram nos extremos: 5 alunos com renda familiar inferior a $\mathrm{R} \$ 700,00$, e outros 12 acima de $\mathrm{R} \$$ 7.000,00.

A maioria dos jovens que responderam a questão sobre religião se declararam católicos/cristãos, somando 119. Depois disso a segunda maior religião entre os 
participantes é a evangélica, 53; não possuem, ateus e agnósticos, são 32; protestante, 3, e espírita, 2. Os que não declararam foram 52 dos participantes. Adventista, luterano, deísta, jhainista, budista de Nitiren Daishonin, mórmon, dentre outras, aparecem com um fiel cada.

Desconsiderando os resultados dos não-declarados, podemos localizar a maior parte dos candidatos como sendo divididos entre mulheres e homens, com preponderância das primeiras, de classe média-alta, no geral religiosos, que seguem alguma vertente do cristianismo. Não obstante, salvo exceção no caso do pertencimento étnico-racial para os alunos do Ensino Fundamental (que se identificam em maioria como pardos) este perfil é o majoritário em todos os grupos onde a coleta foi realizada.

\subsection{Questões Metodológicas}

Para a figura que será apresentada a seguir, algumas considerações devem ser feitas. Existem, dentro dela, quatro elementos nos quais a análise foi embasada. São eles: os nós; o tamanho dos nós; a cor dos nós; as arestas.

"Nó» é como são chamados os diversos círculos presentes na imagem. Cada um deles corresponde a uma palavra do conjunto de narrativas. O tamanho do nó corresponde à quantidade de ligações que uma palavra estabelece com as demais. Quanto maior, mais significativa é a palavra no conjunto. A cor do nó se refere à "modularidade». Ela distingue aquelas palavras que possuem uma conexão maior entre si, formando comunidades e subgrupos. "Aresta», por fim, são as linhas que interligam os nós. Elas permitem visualizar as palavras que tem e as que não tem relação entre si, além de indicar o «peso» dessa ligação a partir de sua largura.

Além disso, outra consideração é digna de nota. Das 4014 palavras diferentes utilizadas pelos participantes, apenas 135 são encontradas nos grafos. Isto se deve a dois motivos. O primeiro é a limpeza mencionada anteriormente. Depois, são apresentadas nos grafos apenas as palavras com uma frequência mínima de 20 repetições. Ora, palavras com uma, cinco ou dez repetições apenas não assumem relevância no interior das 277 respostas e 27131 evocações de palavras. Inseri-las, ademais, poderia poluir o grafo e desfocar a atenção de elementos mais frequentes e fundamentados.

\subsection{Nação}

Uma visualização rápida do grafo que trazemos revela diversas nuances que serão confirmadas quando aprofundarmos a análise. A característica mais superficial encontrada são os elementos que compõe o conjunto das narrativas. Aquelas particularidades que permeiam toda e qualquer narrativa (personagens, enredo e acontecimentos), conforme Sant et al. (2015, p. 343), estão presentes aqui, conforme podemos ver na figura abaixo: 


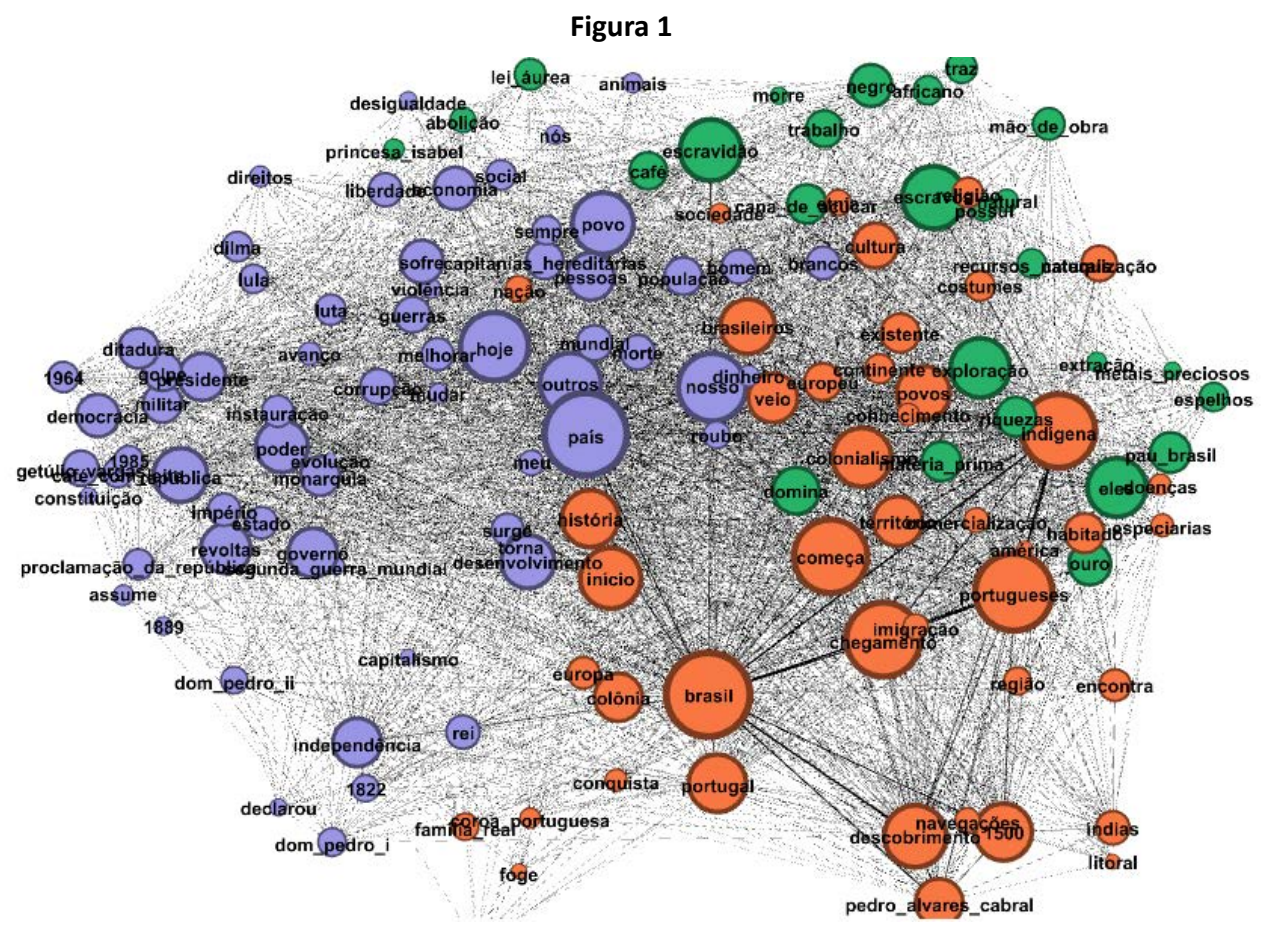

Fonte: O autor, 2018.

Elas são assinaladas pelo conceito de narrativa mestra (Carretero; Van Alphen, 2014). Essa afirmação é comprovada quando analisamos minuciosamente o grafo à luz do conceito. A primeira das premissas da master narrative é a organização das narrativas em termos de inclusão/exclusão. É claro que, esse princípio é comum a toda e qualquer narrativa, destarte o fato de nenhuma ser extensa ou completa o bastante para incluir todos os personagens, eventos e enredos sem excluir nenhum outro. Se pensarmos discriminando cada um dos elementos, porém, vemos que há uma tendência: existe um predomínio de termos e palavras que ou enfatizam o dominador, "vencedor» da história, ou que se adequam a uma história «tradicional», oficial.

Nesse sentido, grupos pertencentes às minorias, como os indígenas, os negros e as mulheres, aparecem à margem das narrativas, sem ter nenhum personagem como representante. A exceção é o nó "dilma», referente a uma personagem feminina. Mesmo nesse caso, porém, o que foi mencionado é atestado: trata-se de um líder político, uma figura de destaque. Os personagens - para se ater a eles são, no geral, compostos pelos "grandes heróis», característicos daquela história tradicional, oficial. O mesmo é válido para as datas e fatos mencionados, todos eles relacionados às trajetórias de criação do Estado-nação em âmbito macro-políticamente. 
A segunda premissa trata do estabelecimento de identidade entre o narrador e o passado histórico. Apenas com a visualização das palavras evocadas podemos atestar sua presença. No centro da imagem, "nosso» tem certa relevância. Seu tamanho demonstra que esse nó tem uma quantidade razoável de ligações. Essa palavra carrega ao mesmo tempo dois sentidos ocultos. Primeiro, ela demonstra posse: "meu». Essa posse entretanto, não é exclusiva, mas compartilhada com um coletivo. Esse é o segundo sentido. Esse coletivo, por sua vez, o «nós», só pode existir na contramão de um "não-nós», ou seja, um coletivo diferente, um "eles», os quais não fazem parte do meu grupo, da minha história, do meu país. Dessa maneira, é palpável o estabelecimento dessa identidade, com "brasil» e com "país», conforme podemos visualizar no grafo. Essas palavras, a princípio, não significam o passado, podendo ser elas mesmas relativas ao país Brasil presente. Como veremos adiante, porém, o tempo presente quase não é mencionado; e esse «brasil» é um brasil anacrônico.

O próximo constituinte do conceito de narrativa mestra é a construção das narrativas a partir de temas que podem assumir caráter teleológico. Duas palavras, uma à direita do grafo e outra mais central, "exploração» e "desenvolvimento», parecem ser os motes condutores dessa história. Orbitando a primeira das palavras, vemos uma variedade de outras palavras relativas às riquezas naturais de terra brasilis, como "recursos», "riquezas», "matéria_prima», "ouro», "pau_brasil»e "metais_preciosos». Nessa mesma localização, palavras relativas ao «indígena», e às chagas pelas quais passou, como «doenças» e, mais acima "escravização». No outro lado, do desenvolvimento, seu estado só passa a ser atingido no momento do «início». Se de um lado assume-se a exploração que marca a história do Brasil, sobretudo ligado ao indígena, de outro, é entendido que isso pode ter ocorrido às custas de um desenvolvimento, que no «início», só pode ser atribuído ao europeu.

É esse mesmo «início» que configura a quarta e última premissa, que diz respeito a uma visão romântica da própria concepção de nação e de nacionalidade. 0 «brasil» nessas narrativas, parece ter algumas tônicas bem definidas. As palavras "início», "começa», "chegamento» e "descobrimento» marcam a história de um país e de um povo que data da chegada dos colonizadores nessa terra. Não existe uma noção de construção do Brasil e do brasileiro. Os dois, pelo contrário, são vistos como preexistentes à própria criação do Estado brasileiro, e do reconhecimento do cidadão. Trata-se, portanto, de uma ideia de Brasil e de brasileiro, anacrônicas.

Outro elemento das imagens que pode revelar informações importantes são os grupos modulares, que refletem também tendências nas narrativas. Na parte inferior do grafo organiza-se um grupo que está ligado majoritariamente aos temas do Brasil colonial, sobretudo os primeiros momentos dos portugueses nestas terras, desde o «descobrimento» ou "chegamento». Em suma, o que é visto pelos alunos como o «início» ou o «começo» da história do Brasil e do próprio Brasil. Esse 
pedaço representa $32,85 \%$ dos nós do grafo, o que demonstra o grande espaço dado a este momento pelos jovens ao escrever a história do Brasil.

Depois, acima, em verde, vemos um grupo modular que se organiza em torno de dois itens principais, a questão da identidade, tendo como atenuante o elemento de posse, exemplificado no nó "eles». O segundo item, mais disperso, abrange diversos nós que dizem respeito ao aspecto econômico e de relações de produção. Esse grupo agrega 18,98 \% dos nós no grafo. É o menor dos três.

O último grupo agrega elementos mais variados temporalmente, indo desde a colônia até os períodos republicanos e as ditaduras que os atravessam. Existe aqui uma maior presença de datas que refletem a identidade deste grupo: os elementos políticos ligado à história brasileira. Existe uma maior presença de datas, personagens, fatos e menções às tradicionais divisões da história do Brasil desde suas configurações políticas: «república», império» e "ditadura». Mesmo que ela também congregue elementos políticos e aborde os três períodos mencionados, não existe, porém, uma menção direta à taxação usada na divisão da história política do Brasil, como mencionamos linhas acima. Elas dividem espaço, também, com uma história mais recente do Brasil. Neste ínterim, podemos destacar as palavras «lula», "dilma», "corrupção», e, podendo melhor exemplificar esse fenômeno, a palavra "hoje», que assume um papel central no grupo modular. Esse grupo, por fim, representa a maior porcentagem dos nós do grafo somando 48,18\%.

Ainda pensando a questão da temporalidade, destaca-se o fato de que não existe a presença de menções ou referências em relação ao futuro, mesmo que hajam gerações de sentido atribuídas ao passado a partir de temas gerais, como exploração e o progresso supramencionados, e ao presente, como parece ser o caso da "corrupção».

Podemos ainda fazer alguns apontamentos ligados a outras particularidades dessas nossas fontes na perspectiva de destacá-las. Já dissemos que no tocante ao conteúdo vemos a exígua presença, em ambos os casos, de figuras ligadas aos movimentos marginalizados e da própria massa. Quanto aos últimos, existem menções a palavras como "pessoas», "povo», "sociedade» e "população». Esses agentes assumem certa centralidade, quase que formando um subgrupo à parte devido a sua proximidade, como podemos ver na parte superior central do grafo. A maioria dos agentes são coletivos, como "portugueses», "brasileiros», «indígena» e "negro», aparecendo oito vezes no grafo. Os agentes individuais, como "getúlio_vargas», por exemplo, são também oito. A centralidade porém, é maior no caso das figuras coletivas, o que demonstra que são eles os grandes agentes na história da narrativa desses jovens.

As narrativas mostram-se recheadas de menções a determinados fatos como a "proclamação_da_república», declaração da independência no encontro de "declarou» e "independência»; "golpe» e "militar», para se referir ao golpe de 1964; "abolição» e "escravidão», no tocante à abolição da escravatura; além de 
"descobrimento", "chegamento», entre outros. Isso se junta à já mencionada evocação de elementos políticos e econômicos em primazia, de maneira a delinear os contornos do nosso conjunto narrativo, que, no geral tratam-se de escritos organizados a partir de datas e fatos que priorizam elementos políticos e econômicos, tendo como tônica o desenvolvimento e a exploração - que parecem ser perpetrados em detrimento um do outro -, estimulados por coletivos, ou por indivíduos específicos, que são os protagonistas dessa história.

Nesse meio termo o "eu», ou seja, o narrador da história não tem espaço, se não no interior dos grandes grupos, do "povo», da "população», dos "brasileiros». Some-se a isso a exígua presença dos tradicionalmente excluídos da história e podemos concluir que existe ainda uma forte remanescência de uma história tradicional nas narrativas, onde os agentes não são os indivíduos comuns, mas indivíduos singulares, ou então coletivos. Os coletivos populares, dessa maneira, podem ser entendidos mais como uma promessa ligada ao presente, do que como os agentes de fato. O que excluí de vez por todas o protagonismo das pessoas "mundanas», não pertencentes às elites políticas e econômicas dominantes.

Enquanto isso, a história é apreendida na esfera exclusiva do passado. Temas relativos ao presente são encontrados, como dissemos, mas eles são figurantes se contrastados ao espaço destinado ao passado. O futuro, por sua vez, nem mesmo é digno de nota. E na medida em que existe uma confusão entre passados, onde a atribuição da nação e da nacionalidade é apresentada de maneira anacrônica - e ainda romântica, teleológica, exclusiva e binária -, podemos dizer que uma narrativa mestra permeia a narrativa desses jovens. Suas origens e seus locutores, entretanto, não é possível discriminar.

Na medida em que a desestruturação das narrativas mestras não ocorreu, podemos atribuir que os participantes, no conjunto, produziram narrativas enquadradas pela tipologia de Rüsen como tradicional. A ausência de perspectivas de futuro, entretanto coloca entraves a essa catalogação, já que a relação entre os três tempos, desde o presente, não é concluída.

Por fim, há de se mencionar a confusão feita pelos alunos entre pátria, estado, país e nação no contexto histórico de suas narrativas. Essa informação é importante para apreendermos em definitivo o lugar do conceito de nação em suas diferentes esferas temporais. No passado mais longínquo presente nos textos, em meados do século XV, momento em que os jovens associam o começo da história do Brasil; país, estado e nação, não existem. O lugar da nação, dessa maneira, é anacrônico e marcado pelo desenvolvimento/exploração, promovida pelos heróis em detrimento de nativos indígenas e escravizados. No presente, a nação é atribuída ao povo e às pessoas; sua marca é a do melhoramento, do avanço e da evolução, mesmo que sob a sombra da corrupção, de guerras, de violência e de luta. O futuro, entretanto, como já assinalamos, não é palpável nesse conjunto analisado. 


\section{CONSIDERAÇÕES FINAIS}

As noções de desenvolvimento veiculadas pelos textos produzidos pelos jovens, em consonância às que marcam um melhoramento e um funcionamento relacionados à nação denotam o caráter de progresso que é dado ao tempo, embora haja nesse intermédio, corrupção, exploração, desigualdade, morte, escravidão, dentre outros infortúnios. Os indivíduos não assumem protagonismo individual, salvo grandes «heróis». Quando as massas entram em cena são corporificadas nos coletivos. Pessoas, povo, população e sociedade, porém, são todas nomenclaturas que retratam também o "eu», mas que, sendo palavras de gênero neutro, mascaram particularidades relativas ao gênero, e também à classe e à raça, funcionando de maneira a alienar as ambiguidades, solapando as diferenças e traduzindo os discursos padronizados que são encontrados em História, sobretudo quando se trata daquela «tradicional».

Nessa perspectiva, sabemos o sentido dado ao tempo, os agentes dele, mas, ainda assim, a noção sobre "o que eu posso fazer no futuro?» é ausente. Na competência do narrar, esses jovens conferem sentido ao passado, desde sua interpretação. Porém, mesmo que se incluam como agentes, não é aparente a tradução de suas experiências (mesmo que lá elas estejam) e ainda menos o estabelecimento de perspectivas para orientação temporal. 0 que podemos supor é que o caráter quase que "higienista» das narrativas, o que comentamos no parágrafo anterior, pode ressaltar o perfil dos participantes: brancos, cristãos e de classe média. Uma inquirição de subgrupos étnicos-raciais, de gênero e classe, entretanto - empreitada para uma outra pesquisa - pode revelar se as contradições são inexistentes e servem à finalidade de «equilibração» da narrativa nacional, por exemplo, ou se elas acabam sendo apenas invisibilizadas mediante o todo.

Se a ideia de nação não é manifesta no futuro, podemos atribuí-lo à «mudança» que se encontra ao lado da "corrupção» no nosso grafo. São as mazelas do presente, as possíveis causas de ausência de futuro. Se essa ausência reflete negligência, desimportância ou falta de perspectivas, não temos como saber. A construção da nação no futuro, entretanto, será dada por estes jovens assim como por tantos outros como eles. É na convergência da nação presente e da nação passada que esse delineamento será dado. Resta saber de que maneira será conduzido, já que os agentes e o cenário já estão definidos. A participação efetiva deles, entretanto, passa pelo reconhecimento de sua agência na história. Esse e outros princípios - como a desconstrução de narrativas mestras e o aprimoramento da consciência histórica - passam pelo ensino de história. Ensinar o passado com perspectivas de futuro, nesse sentido, é uma tarefa que semeia o presente e colhe os frutos no futuro de todos e no passado de cada um. 


\section{REFERÊNCIAS BIBLIOGRÁFICAS}

Anderson, B (1989). Nação e consciência nacional. São Paulo: Ática.

Barca, I.; Schmidt, M. A. (2013). La consciencia histórica de los jóvenes brasileños y portugueses y su relación con la creación de identidades nacionales. Educatio Siglo XXI, 31(1), pp. 25-46.

Barom, W. C. C. (2016). As publicações do projeto Jovens e a História (2007-2014): metodologia, conceitos, temáticas, abordagens e algumas conclusões. História \& Ensino, 22(1), pp. 71-90.

Bruner, J. (1991). The narrative construction of reality. Critical Inquiry, 18(1), pp. $1-21$.

Bruner, J. (1990). Acts of meaning: four lectures on mind and culture. Harvard University Press.

Carretero, M.; Van Alphen, F. (2014). Do master narratives change among high school students? A characterization of how national history is represented. Cognition and Instruction, 32(3), pp. 290-312.

Cerri, L. F.; Amézola, G. de. (2007) Los jóvenes brasileños y argentinos frente a la Historia. Una investigación intercultural sobre la enseñanza y el aprendizaje de la Historia. Revista de Teoría y Didáctica de las Ciencias Sociales, 2, pp. 31-50.

Cerri, L. F. (2000). Ensino de história e nação na publicidade do milagre econômico: Brasil: 1969-1973. 287p. Tese (doutorado) - Universidade Estadual de Campinas, Faculdade de Educação, Campinas, SP. Disponível em: <http://libdigi.unicamp. br/document/?code=vtls000276907>. Acesso em: 27 mar. 2017.

Hobsbawn, E. J. (1990). Nações e nacionalismo desde 1780 - programa, mito e realidade. Rio de Janeiro: Paz e Terra.

Kusnick, M. R.; Cerri, L. F. (2014). Ideias de estudantes sobre a história: um estudo de caso a partir das representações sociais. Cultura Histórica e Patrimônio, 2(2), pp. 30-54.

Lee, P.; Ashby, R. (2001). Empathy, Perspective Taking, and Rational Understanding. In O. L. Davis et al., Historical empathy in the social studies (pp. 21-49). Lanham, MD: Rowman \& Littlefield. 
Rüsen, J. (1987). Explicação narrativa e o problema dos construtos teóricos de narração. Revista da Sociedade Brasileira de Pesquisa Histórica, 3, pp. 97-104.

Rüsen, J. (2007). História Viva: teoria da história III - formas e funções do conhecimento histórico. Editora Universidade de Brasília.

Rüsen, J. (2010). O desenvolvimento da competência narrativa na aprendizagem histórica: uma hipótese ontogenética relativa à consciência moral. Em I. Barca, E. R. Martins, M. A. Schmidt (Orgs.), Jörn Rüsen e o ensino de história (pp. 5177). Curitiba: Ed. UFPR.

Rüsen, J. (2001). Razão Histórica: teoria da história: fundamentos da ciência histórica. Brasília: Editora Universidade de Brasília.

Rüsen, J. (2015). Teoria da História: Uma teoria da História como ciência. Curitiba: Editora UFPR.

Sant, E. et al. (2015). How do catalan students narrate the history of Catalonia when they finish primary education? McGill Journal of Education, 50(2/3), pp. 341362.

Schmidt, M. A. (2008). Perspectiva da consciência histórica e da aprendizagem em narrativas de jovens brasileiros. Tempos Históricos, 12, pp. 81-96.

Silva, T. T. (2000). A produção social da identidade e da diferença. Em T. T. Silva (Org.), Identidade e diferença (pp. 73-102). Rio de Janeiro: Editora Vozes.

Watts, R. (2000). History in Europe: the benefits and challenges of co-operation. Em J. Arthur; R. Phillips, Issues in history teaching (pp. 175-190). Abingdon; New York: RoutledgeFalmer.

Wertsch, J. (1994). Struggling with the past: Some dynamics of historical representation. Em M. Carretero; J. Voss (Orgs.), Cognitive and instructional processes in history and the social sciences (pp. 323-338). Mahaw: Routledge. 